\title{
Dynamic Modeling of Induction Motor Taking Into Account Thermal Stresses
}

\author{
S. LAISSAOUI, D. SEDIRA, A. LADJIMI and M.R. MEKIDECHE \\ Département de Génie-Electrique \\ Université de Jijel \\ Laboratoire d'études et de modélisation en électrotechnique, Université de Jijel (L.A.M.E.L). \\ BP 98 - Ouled Aïssa-Jijel 18000 \\ ALGERIE
}

\begin{abstract}
The study of thermal behaviour is useful to identify causes of failure in electrical machines. This work details a two dimensional model for computing the magnetic and thermal finite element solution of induction motor using a weak coupling algorithm. In order to improve the accuracy of the adopted numerical formulation, the decrease of the electric conductivity with temperature is taking into account.
\end{abstract}

Key-Words: - Induction motor, voltage equations, thermal analysis, coupled problem, finite element method, losses, hot spot, overheating

\section{Introduction}

In different types of electrical energy transducers such as electrical machines, it is important to study the electromagnetic behaviour jointly with the thermal behaviour [1][2]. Two interactions justify such a coupled view.

- Most thermal energy sources heating up these devices are in fact electromagnetic losses. Generally, these heat sources are a function of the local electromagnetic field. Therefore they represent a coupling of the electromagnetic field to the thermal field.

- Many material characteristics playing a role in the electromagnetic field are depending on the local temperature. For instance, the electrical conductivity of a copper conductor may change about $30 \%$ over the temperature interval of some $100{ }^{\circ} \mathrm{C}$ in which most electrical machines operate.

In this paper the implementation of a coupled electromagnetic-thermal field problem is presented. In order to estimate the thermal impact on the induction motors a comparison between two simulations is realized. The first simulation is done with a constant electric conductivity. In the second the dependency of the electric conductivity on temperature is taking into account.

\section{Electromagnetic problem}

Distributed heat sources are calculated by solving the voltage source eddy current problem, accounting for saturation in a dynamic rotating model.

\subsection{Field equations}

Magnetodynamic complex formulation for the electromagnetic problem is used.

$\left\{\begin{array}{l}\nabla \times(v \nabla \times \boldsymbol{A})=\boldsymbol{J}_{e x} \quad \text { in stator windings } \\ \nabla \times(v \nabla \times \boldsymbol{A})=0 \quad \text { in air gap } \\ \nabla \times(v \nabla \times \boldsymbol{A})+j \omega_{S} g \sigma_{E}+\sigma_{E} \nabla V=0 \text { in rotor windings (1) } \\ \nabla \times(v \nabla \times \boldsymbol{A})=0 \quad \text { in core materials } \\ \boldsymbol{A}=0 \quad \text { on the outer boundary }\end{array}\right.$ where

$\boldsymbol{A}$ : Magnetic vector potential, $\boldsymbol{J}$ : Inductor current density, $v$ : Reluctivity, $\sigma$ : Electric conductivity, $V$ : Scalar potential, $\omega_{\mathrm{s}}:$ Pulsation of the rotor currents, $g$ : Slip of the rotor.

\subsection{Voltage equations}

External voltage source is connected externally to the finite element region. For this case stator equivalent circuit equation is given by:

$U_{i}=R_{\text {tête }} i_{\text {phi }}+j \omega_{s} L_{\text {tête }}+\Delta V_{i}$ with $i=1,2,3$

where 
$R_{\text {tête }}$ : End windings resistance, $L_{\text {tête }}$ : End windings inductance, $V$ : Scalar potential difference between the ends of stator's conductors.

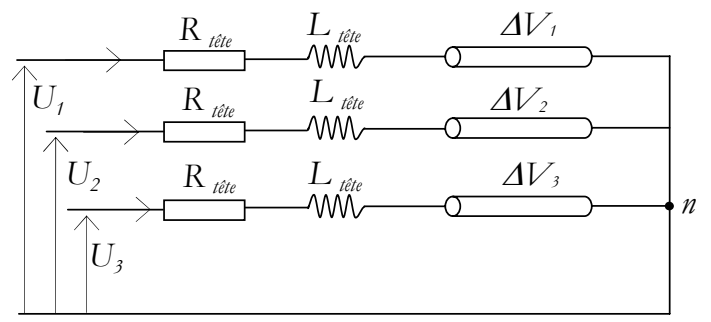

Fig.1 Stator equivalent circuit

Voltage equations are not constructed for the rotor winding because we assumed that the ends of the rotor are equipotential surfaces of the scalar potential.

\subsection{Coupling field equations to voltage equations}

Field and voltage equations should be solved together as a system of equation [3].

$$
\begin{aligned}
& \text { Magnetic matrix }-\sqrt{-} \text { Coupling matrix }
\end{aligned}
$$

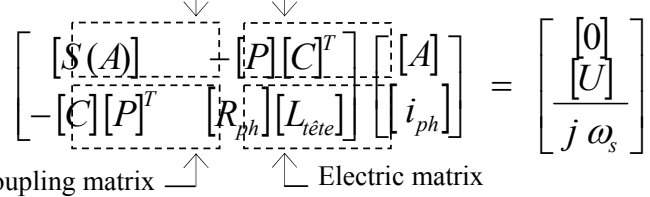

where

$U$ : Phase's voltage vector, $i_{p h}$ : Phase's current vector.

Because of the nonlinearity of the core materials the system of equations must be solved iteratively (fixed-point technique).

The heat sources associated with magnetic field are Joule losses caused by the driving currents and the induced eddy currents. Iron losses occur in ferromagnetic materials subject to hysteresis phenomena.

\section{Transient thermal problem}

The heat generation $q$ of electromagnetic nature results in coupling of the source term of the righthand side of the thermal equation. Heat transfer inside the machine is described by the following equations:

$\left\{\begin{array}{c}\rho C_{p} \frac{\partial T}{\partial t}=\nabla \cdot(\lambda \nabla T)+q \quad \text { in all the domain } \\ -\frac{\lambda \partial T}{\partial n}=\left(h_{c}+h_{r}\right)\left(T_{p}-T_{r e f}\right) \text { on the boundary }\end{array}\right.$

where
$T$ : Temperature, $\rho$ : Specific mass, $C_{p}$ : Specific heat, $\lambda$ : Thermal conductivity, $h_{c}$ : Convection coefficient, $h_{r}$ : Radiation coefficient, $T_{a}$ : Ambient temperature, $n$ : Outer normal vector to the boundary.

The finite element model of the heat conduction problem with mixed boundary conditions (convection, radiation) and thermal sources is given by the following matrix equation [4]:

$$
[K] \frac{\partial[T]}{\partial t}+[M][T]=[F]
$$

where

$[K]$ : Thermal capacity matrix, $[M]$ : Thermal conductivity matrix, $[F]$ : heating sources vector.

Contact resistances and thin insulation layers are considered in order to obtain a realistic temperature distribution [5].

\section{Coupled electromagnetic-thermal problem}

Weak coupled modeling between electromagnetic and thermal phenomena is adopted. In order to obtain solutions of the coupled problem two approaches are used:

- The first approach consists of solving the electromagnetic and thermal problems in successive steps with up-dating the reluctivity.

- In the second approach the equations are solved sequentially with up-dating the reluctivity and the electric conductivity.

The two coupled models are applied on a threephase induction motor.

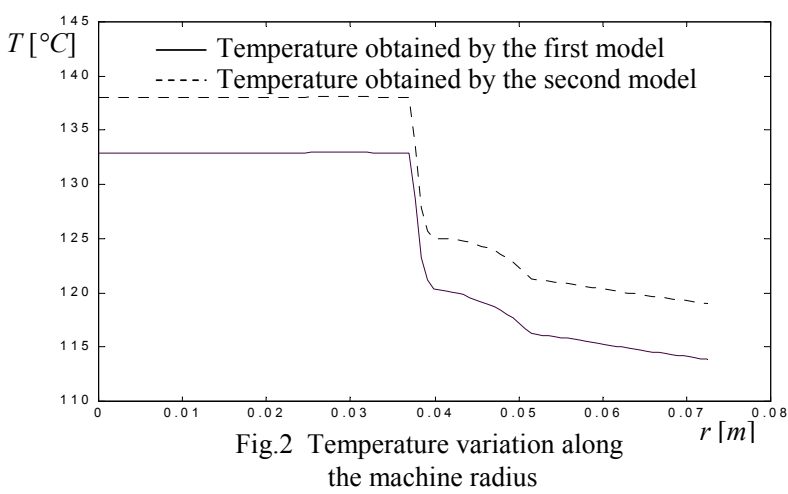

In order to analyze the effect of the thermal dependency of electric conductivity and the contribution of the iron losses for the temperature raise some results are presented in table 1. 


\begin{tabular}{ll}
\hline Without iron losses, constant conductivity & $T_{\operatorname{Max}}\left[{ }^{\circ} \mathrm{C}\right]$ \\
\hline Without iron losses, thermal dependent conductivity & 128,86 \\
\hline With iron losses, constant conductivity & 134,13 \\
\hline & 132,5 \\
\hline
\end{tabular}

The computed 2D magnetic and 2D thermal solution fields since the decrease electric conductivity is taking into account are given in Figure. 3 and Figure. 4.

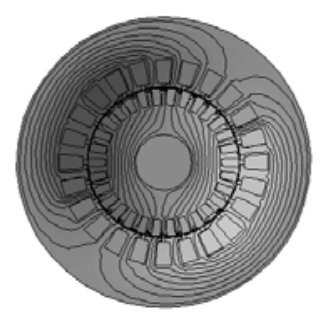

Fig.3 Equipotential lines of the vector potential at slip $5 \%$

Dark regions indicate the hottest spots $\left(138^{\circ} \mathrm{C}\right)$, i.e., the rotor. It can be seen that a considerable thermal gradient between stator and rotor is noted (Fig.4).

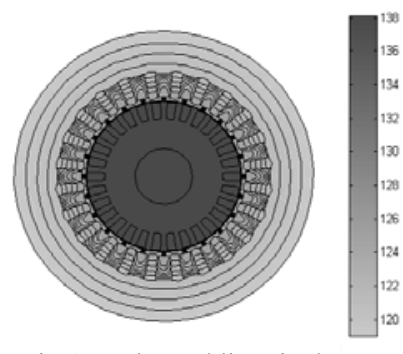

Fig.4 Isothermal lines in the induction motor

The evolution of temperature in different parts of the machine since the decrease electric conductivity is taking into account is shown in figure 5 .

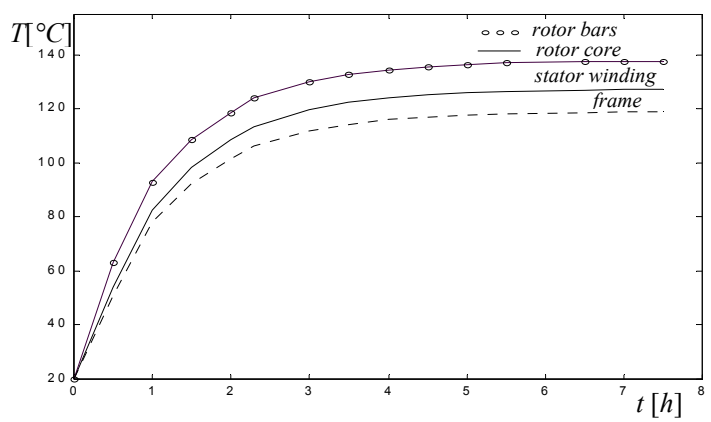

Fig.5 Evolution of temperature in different parts of the machine

\section{Conclusion}

The results presented here, proof that the temperature dependency of the electric material characteristics must be considered when an accurate simulation of induction motor is required.

\section{References:}

[1] J.P. Bastos, M.F.R.R. Cabreira, N. Sadowski, S.R. Arruda, 'A thermal analysis of induction motors using a weak coupled modeling', IEEE Transactions on Magnetics, vol. 33, $\mathrm{n}^{\circ}$ 2, pp. 1714-1717, March 1997.

[2] Y. Lee, H.B. Lee, S.Y. Hahn, 'Temperature analysis of induction motor with distributed heat sources by finite element method' , IEEE Transactions on Magnetics, vol. 33, $\mathrm{n}^{\circ} 2$, pp. 1718-1721, March 1997.

[3] E. Vassent, G. Meunier, A. Foggia, 'Simulation of induction machines using complex magnetodynamic finite element method coupled with the circuit equations', IEEE Transactions on Magnetics, vol. 27, $\mathrm{n}^{\circ}$ 5, pp. 4246-4249, September 1991.

[4] G. Dhatt et G. Touzot, 'Une représentation de la méthode des éléments finis', Ed. Maloine, Paris, 1984.

[5] J. Driesen, R.J.M. Belmans, K. Hameyer, 'Finite element modeling of thermal contact resistances and insulation layers in electrical machines', IEEE Transactions on Magnetics, vol. 37, $\mathrm{n}^{\circ}$ 1,pp. 15-19, January/February 2001. 